\title{
The Characteristics and the Dominant Factor of Fracture Development of the Lower Silurian Longmaxi Formation Black Shale in Sangzhi
}

\author{
Xiaolin $\mathrm{Jin}^{1}$, Chenglong Zhang ${ }^{1}$, Chengdong $\mathrm{Mao}^{2}$ and Xufeng $\mathrm{Li}^{1}$ \\ ${ }^{1}$ Center for Hydrogeology and Environmental Geology, China Geological Suvery, Baoding Hebei, China \\ ${ }^{2}$ Ministry of Land Resources of the People's Republic of China, Beijing, China
}

\begin{abstract}
Based on the analysis of tectonic faults in Sangzhi area, black shales fracture characteristics and controlling factors of the Longmaxi formation of Lower Silurian are studied. That fracture distribution of the study area is mainly controlled by fault, where the NE-trending fault system plays the most significant role. Fracture zones are located in the anticlinal axis, as well as at the stress concentration ,such as near the fault or in intersection of different fault zone.Dispersion of fracture strike and its density are controlled by the fault line, fracture develops near the fault line, which strike is mainly north-east. It contains high content of brittle mineral which becomes friable rock and has well-developed fracture.
\end{abstract}

Keywords-characteristics; dominant factor; fracture development; the Lower Silurian Longmaxi formation; Sangzhi; black shale

\section{INTRODUCTION}

The successful development of North American marine organic-rich shale prompts the research of shale reservoirs into a new phase(1-3).Organic-rich shales are both source rocks and a reservoir in term of shale gas reservoir, the storage space can be divided into fissure type and pore-fissure compound type , and the fissure type occupies an important position(2,4). Lower Silurian Longmaxi formation marine organic-rich shale has favorable formation conditions for shale gas development in Sangzhi, but this area has the relative complexity tectonic movements and fractures, cracks complicated.In response to this situation, we carry out research on fracture characteristics and main controlling factors of the Lower Silurian shale gas reservoir in Sangzhi.

\section{ORGANIZATION OF THE TEXT}

\section{A. Geological Background}

Sangzhi is the transformation of the area where between the Tethys tectonic domain and the Pacific tectonic domain, located in the Yangtze platform fold belt, has experienced many intense tectonic movements since the Luliang movement period, shaped the complex tectonic framework in multiphase tectonic superimposition, interference, the transformation (Fig. 1).As to stratigraphic division, belonging to transition zone between the Yangtze area and Jiangnan area. In Lower Paleozoic, developed the Lower Cambrian Niutitang formation and Lower
Silurian Longmaxi formation (5). Lower Silurian Longmaxi formation is a set of rich graptolite black carbon, siliceous shale, reflected sedimentary background of part limited coastal to shallow sea basin as early as the early as Lower Silurian.Widely distributed in the whole Sangzhi region, black, green and yellow mud shale thickness of stratum, a high content of organic carbon and high maturity, is the preferred formation for shale gas exploration in the study area.

\section{BASIC GEOLOGICAL CHARACTERISTICS AND FRACTURE DEVELOPMENT CHARACTERISTICS}

\section{A. Basic Geological Characteristics}

Lower Silurian Longmaxi formation shale is of rich organic matter, exposed more, thickness larger, at $90-200 \mathrm{~m}$, and the whole is greater than $90 \mathrm{~m}$. New formation is exposed more in synclinal area, at the same time syncline area has large stratigraphic dip, so buried deeply, on the contrary, buried shallowly in the anticline zone.The development of fracture impact on the objective layer depth obviously, especially fall plate during the period of synsedimentary fault, buried deeper obvious. The content of organic carbon change largely, be close to $1 \%$ on average,in plane, high organic carbon content are mainly concentrated in Guandiping, Sangzhi, and it reduces gradually from central to sides on the whole. Maturity is more than $1.5 \%$ on average, be in stage of high to over maturity. The average porosity is $5.6 \%$ in the study area which in the northwest of hunan, and pore throat at $13.78 \mathrm{~nm}-15.19 \mathrm{~nm}$, $14.53 \mathrm{~nm}$ on average, belongs to low porosity low permeability reservoir, therefore, the degree of fracture development affect the shale gas exploration and development directly in this area.

\section{B. Fracture Development Characteristics}

Based on the results of research on the Lower Silurian Longmaxi black shale outcrop in the study area, we find that the target mainly develop tectonic fracture, including tension cracks and shear cracks. Tension cracks in groups often exist in parallel, have clear direction and rule distribution (Fig. 2.a). The shear fracture generally cut layer deeply, have stable occurrence and far extending. Crack displays group, every group's cutting relation is obvious(Fig.2.b). Three different directions fractures cut each other. This reflects that the study area has experienced several tectonic movements(Fig. 
2.c).Tectonic fracture filling is very common, mostly calcite filling, aslo pyrite, clay, silica, carbonate, etc . and it have a high filling degree. (Fig .2.d). Field survey also found that fractures are well developed in severe deformation and fault development zone. The fractures in the anticline are mostly tension cracks, where the whole is divergent. The fractures longitudinally through the different rock formations until terminate in the mudstone interlayer. The fracture extend at 5-30cm(Fig.2.e). The formation near fault deform seriously and the degree of fracture is high (Fig .2.f)

\section{THE MAIN CONTROLLING FACTORS OF THE CRACK}

There are many factors that can affect the shale gas reservoir fracture formulation and distribution. Compared with other types of rocks reservoir, the shale reservoir with more plasticity, which is rich in organic matter, has both generality and particularity in controlling factor of fracture development. It can mainly be classified into two reasons, the non-structural factors and structural factors, which are the inner and exterior cause of formulation of shale reservoir respectively.

\section{A. Structural Factors}

Structural factors are external causes for cracks, and the mainly tectonic effects that associate with fracture formation include: (1) when the relatively large Plastic shale layer is in local or regional tectonic stress, the formation will form high angle shear and tensile-shear tectonic fractures by the ductile shear fracture. The tectonic fractures are often associated with fold or fault, group appears, with the level of near-vertical and obvious directivity, have a relatively flat fracture plane. This high angle fractures in shale are mainly developed in the rock, Part of those can cut through the shale layer and extend to the formation of sandstone reservoirs to develop frans-formational fracture(2)The applied area differential stress and tensile fracture width varies linearly. As the applied area of differential stress becomes larger, the fracture zone width increases linearly(6).(3)The fault strike also exert an influence on the development of structural fractures, The study found the fault strike is inversely proportional to the tensile fracture zone width. With the fault strike and applied differential stress increase, tensile fracture zone width presents linearly decreasing trend. (4)Magma intrusion and salt dome will impact favorable for shale fracture(7).

Fault is developed in Sangzhi area, its distribution is mainly north-east direction. Fracture is dense and presented "S" shape and "X" shape in the northeast of the study area. The appearance show that tectonic deformation of Sangzhi region dominated by compression, both have strike-slip properties (Fig. 3.a). Because of the different structural conditions, lithology and the transformation of post-denudation, the phenomenon that syncline have higher altitude and anticline have lower altitude. It can be summarized as" syncline becomes Mountain, anticline becomes valley". The northeast of the study area is composed of multiple directions of the fault system interactional cutting and combining. Sangzhi region generally developed marine carbonate formation rock that is brittle. The fault generally have lager dip angle. Some dip angle is bigger, more than 45 degrees and some sections even upright, some fault surface even erect. The development of folds and faults has obvious control effect on distribution of strata. This is obvious on the outcrop in the west of study area. The dispersion of fracture's density and direction is controlled by fault lines. Under the influence of fault plane, fissures develop near the fault lines at Hongjiayu area of Sangzhi, mostly of them are open and have same direction, which are much to the Northeast and nearly parallel develop. Since ductile shear, some fractures and faults are perpendicular to the strike, with high density and small length. The developmental situation of fractures in Hongjiayu region is similar to the Antrim shale in Michigan Basin (Fig. 3.b)

\section{B. Non-Structural Factors}

The main internal factors which contain lithology and rock mineral composition that control the development of fractured, studies suggest that in the shale minerals such as quartz, feldspar and carbonate higher, the greater the brittleness of shale, in the same tectonic stress, it is easy to form natural fractures and induced fractures, be beneficial for free gas analysis, seepage, and gathered into Gas reservoirs. Quartz-rich black Shales is more brittleness than calcite-rich gray shale, the degree of fracture development is relatively high(8). What's more, feldspar and dolomite are also brittle mineral composition(9). The higher silicon content, the more conducive to the formation of cracks(10). The degree of fracture development is generally positively related to the brittleness of mineral concent in shale.

Texas basin and Arkama basin rich high brittleness mineral content, the content of quartz is greater than $30 \%$, secondly feldspar content is close to $10 \%$, and carbonate mineral content is also greater. Compared to America, Sichuan Weiyuan area also has high brittleness mineral content; quartz can be up to $61.5 \%$, followed by the carbonate content. The fractures development of these three basins has been commercial development of shale gas. Based on the previous survey, the author analyzed experimentally the Lower Silurian Longmaxi 27 shale samples fetched from sangzhi. Found in the study area quartz content from $31.7 \%$ to $91.2 \%$, the average is $56.2 \%$ and the feldspar content at $2.1 \%-2.1 \%$, the average is $7 \%$, and carbonate content is scarce. In general, the brittleness mineral content is close to $60 \%$, belong to relatively brittle shale, and fracture development (Table.1).

\section{CONCLUSIONS}

(1)The objective layer is given priority to cause structural cracks in the study area, and cracks have a group of department, gap by calcite, argillaceous filling, fracture develop in fault and anticlinal axis.

(2)Distribution of fracture development is controlled by fault zone and the north east fracture system play the most significant role.Fracture development zone is located in anticlinal axis, near fault and stress concentration area that intersect of different fault zone.Crack density and direction of the dispersion is controlled by fault line and fracture 
development in where there are fault lines, and direction of fracture give priority to the NE.

(3)Lithology and mineral composition is to control the internal cause of fracture development, the content of brittle mineral is high in Lower Silurian Longmaxi formation in the study area, belonging to the brittle rock, and be beneficial to fracture development in the influence of the tectonic stress.

\section{ACKNOWLEDGEMENTS}

This work was financially supported by the National Natural Science Foundation of China(41272176/D0208), University doctoral fund projects(20110022110007)and National science and technology major projects" Shale gas resource potential assessment in Hunan province" (1212011220802).

\section{REFERENCES}

[1] Jinchuan Zhang, Haikuan Nie, Bo Xu ,et al. Geological condition of shale gas accumulation in Sichuan Basin[J]. Natural Gas Industry, 2008, 28(2): 151-156. In Chinese

[2] Curtis JB. Fractured shale-gas systems [J].AAPG Bulletin 2002, 86(11): 1921-1938.

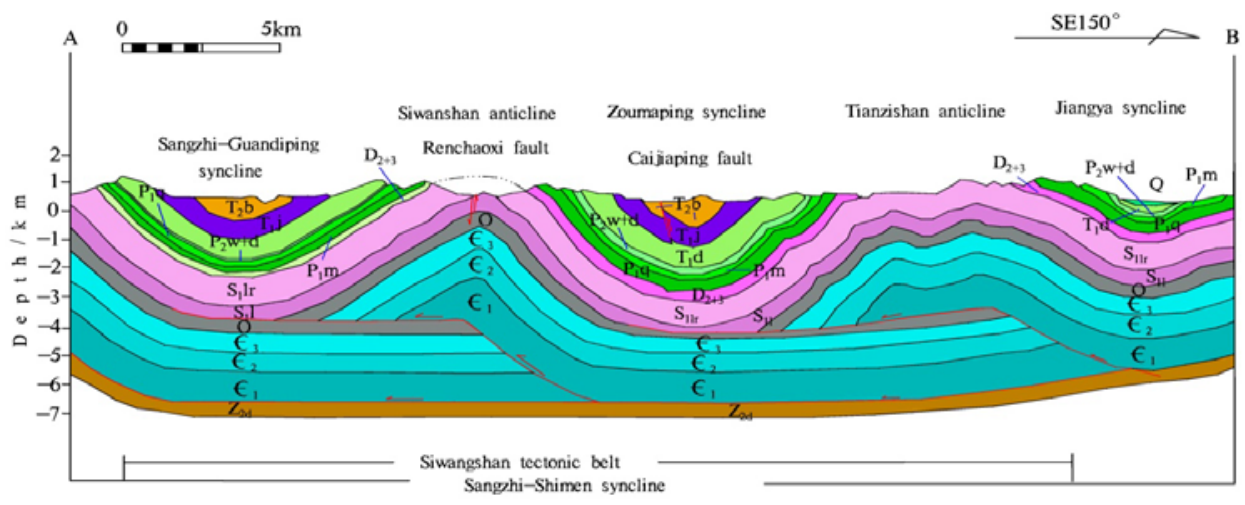

FIGURE I. SANGZHI SYNCLINORIUM SECTIONAL STRUCTURAL VIEW OF TECTONIC BELT.

TABLE I. STATISTICS OF RELATIONSHIP BETWEEN FRACTURE DEVELOPMENT AND LITHOLOGY/MINERAL CONTENT IN SHALE RESERVOIRS.

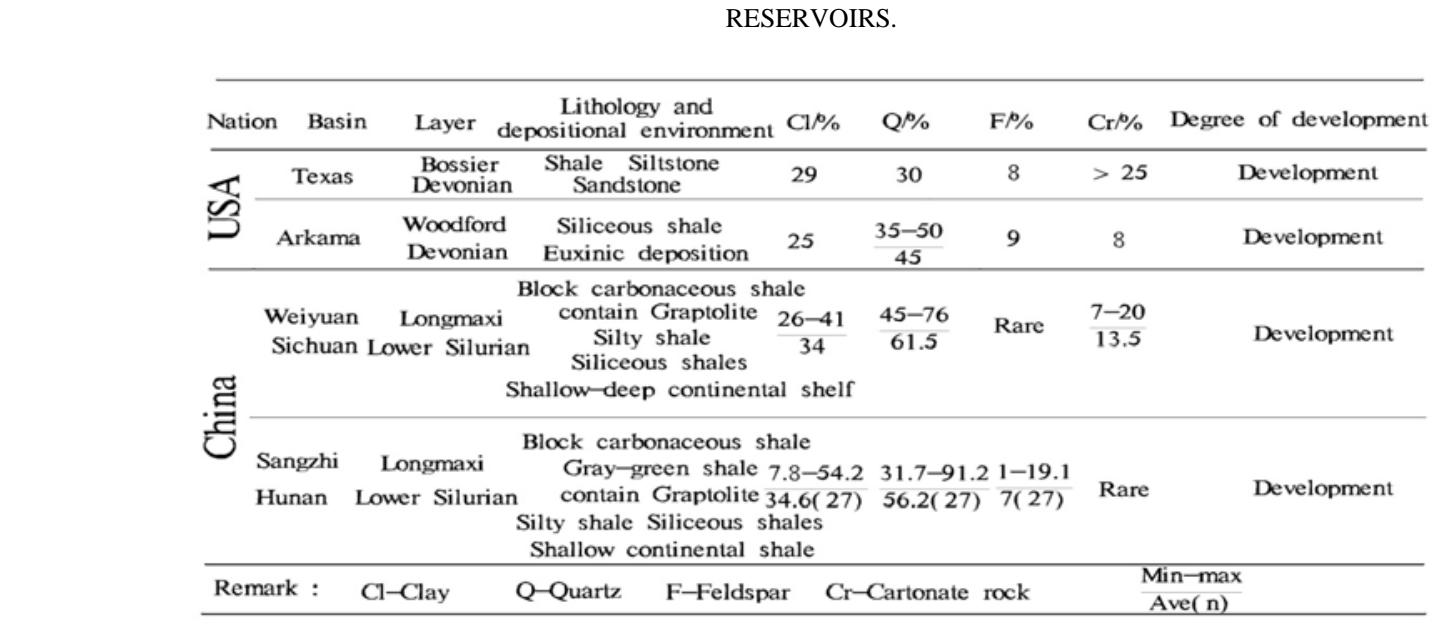

[3] WarlickD.Gas shale and CBM development in North America [J].Oil and Gas Financial Journal, 2006,3(11):1-5.

[4] Xiaoshui Mu, Xiaorong Yuan, Yifang Jia, etal. The formation conditions and the distribution characteristics of the oil pools in the fractures of the shales in Dongpu depression [J].Fault-Block Oil \&Gas Field, 2003, 10(1): 12-14. In Chinese

[5] Dazhong Dong, Keming Cheng, Yuman Wang, etal. Forming conditions and characterisitics of shale gas in the Lower Paleozic of the Upper Yangtze region,Chian[J].Oil \& Gas Geology,2010,31(3): 288-299. In Chinese

[6] Qinglian Zhang, Guiting HOU, Wenqing Pan, etal. Numerical simulation of structural fractures controlled by PiQiang strike-slip fault[J].Oil \& Gas Geology,2010,31(3): 288-299. In Chinese

[7] Fangxing Ning. Fractured shale reservoir formation mechanism of Xianhezhuang in Dongying depression[J].Xinjiang Oil \& Gas, 2008, 4(1): 20-25. In Chinese

[8] Hill D G, Lombardi T E,Martin J P. Fractured shale gas potential in NewYork[J].Nor-theastern Geology \& Environment Science, 2004, 2698: $1-49$.

[9] Nelson R A . Geologic Analysis of Naturally Fractured Reserviors: Contributions in Petroleum Geology and Engineering [M].Houston: Gulf Publishing company.1985:320 theastern Geology \& Environment Science,2004,2698:1-49.

[10] Denghua Li, Jianzhong Li, Shejiao Wang, etal. Analysis the formation of shale gas reservoirs [J]. Natural Gas Industry.2009,29(5):22-26. In Chinese. 

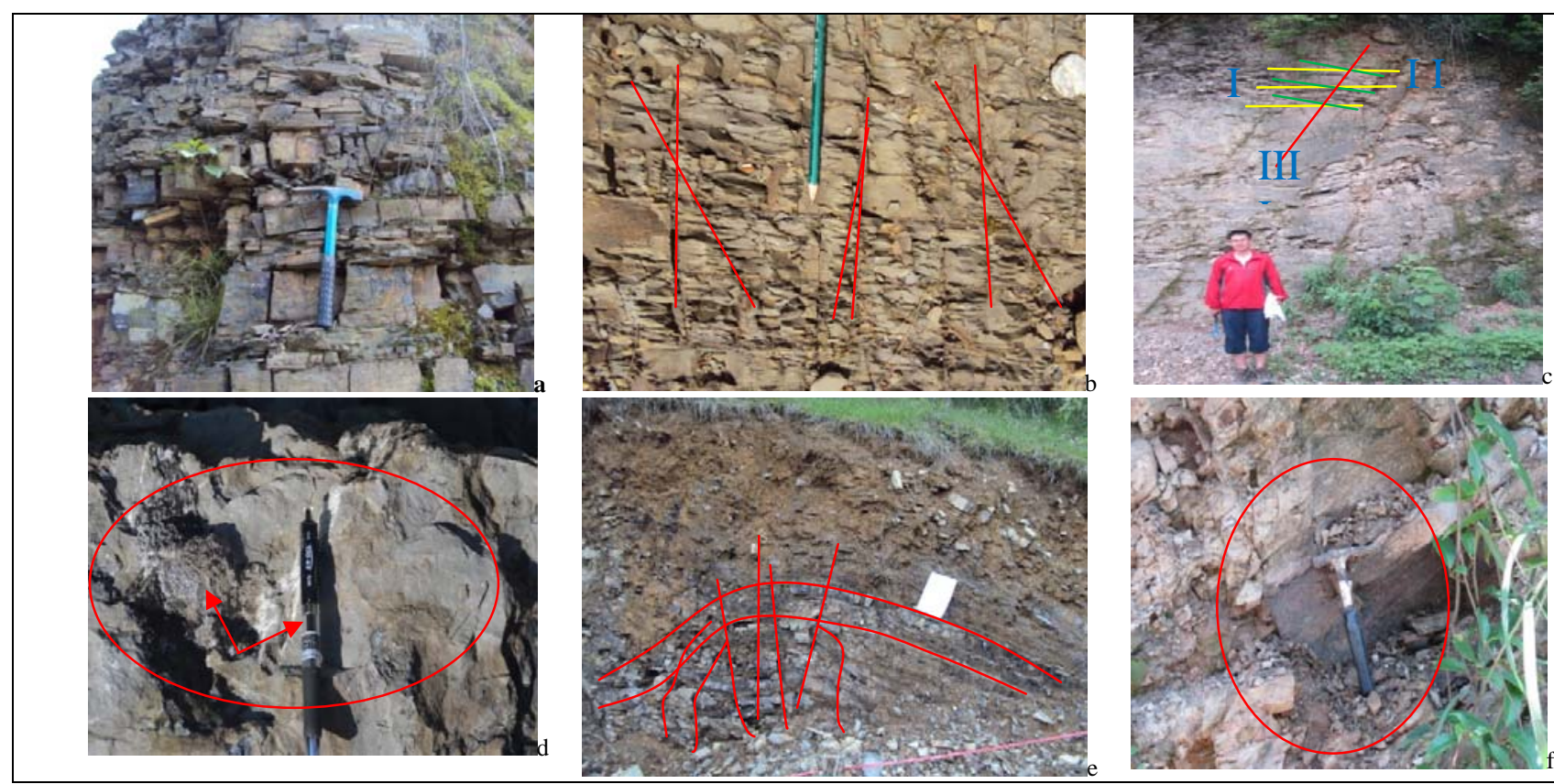

FIGURE II. THE OUTCROP FRACTURE CHARACTERISTICS OF LOWER SILURIAN BLACK SHALE IN SANGZHI. A TENSION CRACKS, PARALLEL IN GROUP,DAMUTANG,SANGZHI.B SHEAR FRACTURE, STABLE OCCURRENCE AND FAR EXTENDING,HONGJIAYU,SANGZHI. C DIFFERENT DIRECTIONS FRACTURES CUT EACH OTHER ,HONGJIAYU,SANGZHI. D CALCITE AND ASPHALT FILLING,SHATAPING,SANGZHI. E FRACTURES DEVELOPED WELL IN SEVERE DEFORMATION AND FAULT DEVELOPMENT ZONE,XIONGJIAWA,SANGZHI.F.FRACTURES DEVELOPED WELL IN FAULT DEVELOPMENT ZONE,SHUITIANYU,SANGZHI.
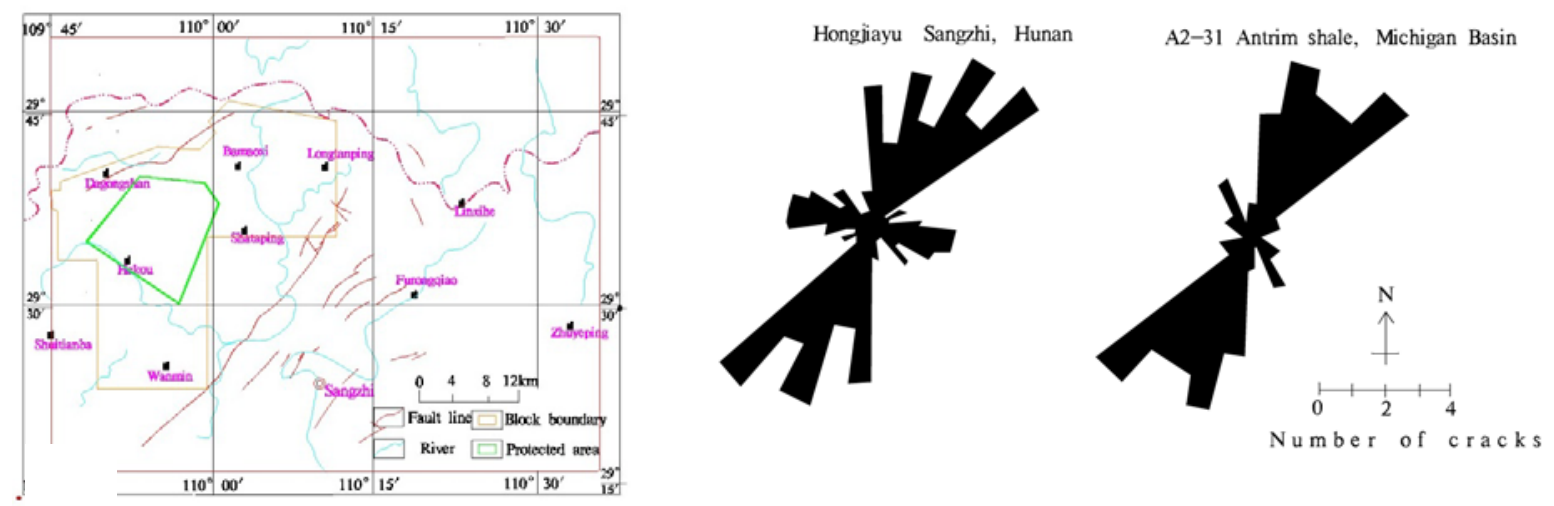

FIGURE III. THE MAP OF THE DISTRIBUTION TREND OF THE FAULT AND CRACK. 